\title{
Ensino da matemática em níveis fundamental e médio: Utilizando jogos como ferramentas didáticas
}

\author{
Teaching mathematics at elementary and high school levels: Using games as teaching tools \\ Enseñanza de las matemáticas en la escuela primaria y secundaria: Uso de juegos como
}

\author{
herramientas de enseñanza
}

Recebido: 04/05/2021 | Revisado: 11/05/2021 | Aceito: 12/05/2021 | Publicado: 29/05/2021

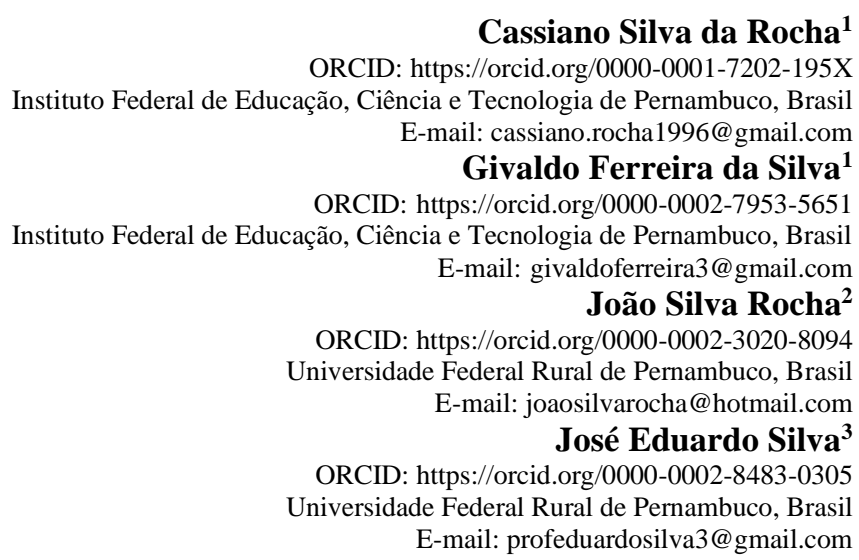

\begin{abstract}
Resumo
As constantes transformações sociais e tecnológicas da sociedade moderna demandam que o Ensino da Matemática esteja em contínuo aperfeiçoamento, buscando propostas pedagógicas que promovam uma aprendizagem contextualizada e crítica. Este trabalho objetiva refletir sobre a influência que as abordagens metodológicas no Ensino da Matemática têm no desenvolvimento cognitivo do estudante e como os jogos podem ser apresentados como recursos didáticos no ensino da matemática. Utilizou-se de uma metodologia de natureza qualitativa, de caráter descritivo, exploratório e analítico, por meio de uma revisão bibliográfica, com análise dos dados baseada em argumentos qualitativos, utilizando artigos publicados na plataforma Google Acadêmico entre os anos de 2017 e 2021. Os resultados demonstram as práticas pedagógicas Modelagem Matemática, Aprendizagem Baseada em Problemas e Ensino Remoto, com prevalência da Prática Pedagógica Tradicional no ensino da matemática. Evidenciou-se o uso da ludicidade com jogos no ensino da matemática como prática pedagógica alternativa e reflexões do repensar a infraestrutura de ensino subsidiando o professor em possibilidades e incentivos na aplicação de novos métodos didáticos como o uso de jogos. Conclui-se que o ensino de matemática prevalece na prática tradicional pedagógica e que mudanças nos métodos de ensino são necessárias, não podendo negligenciar a participação do professor como indissociável ao processo. A utilização de jogos apresenta-se como método alternativo e não substituto aos demais modelos de ensino.
\end{abstract}

Palavras-chave: Ensino de matemática, Ludicidade, Jogos, Práticas pedagógicas, Ensino.

\begin{abstract}
The constant social and technological transformations of modern society demand that the Teaching of Mathematics be in continuous improvement, seeking pedagogical proposals that promote contextualized and critical learning. This work aims to reflect on the influence that methodological approaches in the Teaching of Mathematics have on the cognitive development of the student and how games can be presented as didactic resources in the teaching of mathematics. We used a qualitative methodology, of a descriptive, exploratory and analytical nature, through a bibliographic review, with data analysis based on qualitative arguments, using articles published on the Google Scholar platform between the years 2017 and 2021. The results demonstrate the pedagogical practices Mathematical Modeling, Problem-Based Learning and Remote Teaching, with prevalence of Traditional Pedagogical Practice in the teaching of mathematics. The use of playfulness with games in the teaching of mathematics was evidenced as an alternative pedagogical practice and reflections on rethinking the teaching infrastructure, subsidizing the teacher in
\end{abstract}

\footnotetext{
${ }^{1}$ Graduando em Licenciatura em Matemática pelo Instituto Federal de Educação, Ciência e Tecnologia de Pernambuco - IFPE

${ }^{2}$ Professor e Coorientador pelo Instituto Federal de Educação, Ciência e Tecnologia de Pernambuco - IFPE

${ }^{3}$ Professor e Orientador pelo Instituto Federal de Educação, Ciência e Tecnologia de Pernambuco - IFPE - e-mail:<silva.j.e@ outlook.com>.
} 
possibilities and incentives in the application of new didactic methods such as the use of games. It is concluded that the teaching of mathematics prevails in traditional pedagogical practice and that changes in teaching methods are necessary, and cannot neglect the participation of the teacher as inseparable from the process. The use of games is presented as an alternative method and not a substitute for other teaching models.

Keywords: Mathematics teaching, Playfulness, Games, Pedagogical practice, Teaching.

\section{Resumen}

Las constantes transformaciones sociales y tecnológicas de la sociedad moderna demandan que la Enseñanza de las Matemáticas esté en mejora continua, buscando propuestas pedagógicas que promuevan el aprendizaje contextualizado y crítico. Este trabajo tiene como objetivo reflexionar sobre la influencia que tienen los enfoques metodológicos en la Enseñanza de las Matemáticas en el desarrollo cognitivo del alumno y cómo los juegos pueden presentarse como recursos didácticos en la enseñanza de las matemáticas. Se utilizó una metodología cualitativa, de carácter descriptivo, exploratorio y analítico, a través de una revisión bibliográfica, con análisis de datos basado en argumentos cualitativos, utilizando artículos publicados en la plataforma Google Scholar entre los años 2017 y 2021. Los resultados demuestran las prácticas pedagógicas Matemáticas Modelización, Aprendizaje Basado en Problemas y Enseñanza Remota, con predominio de la Práctica Pedagógica Tradicional en la enseñanza de las matemáticas. El uso de la alegría con juegos en la enseñanza de las matemáticas se evidenció como una práctica pedagógica alternativa y reflexiones sobre repensar la infraestructura docente, subvencionando al docente en posibilidades e incentivos en la aplicación de nuevos métodos didácticos como el uso de juegos. Se concluye que la enseñanza de las matemáticas prevalece en la práctica pedagógica tradicional y que los cambios en los métodos de enseñanza son necesarios, y no se puede descuidar la participación del docente como inseparable del proceso. El uso de juegos se presenta como un método alternativo y no un sustituto de otros modelos de enseñanza.

Palabras clave: Enseñanza de las matemáticas, Lúdico, Juegos, Prácticas pedagógicas, Ensenãnza.

\section{Introduçãa}

A matemática é primordial em diversas áreas do conhecimento, por esse motivo, a compreensão dos seus conceitos pelos estudantes é essencial. Para que isto aconteça, é necessário que as causas que levam às dificuldades e, em muitos casos, a não aprendizagem deste componente curricular sejam investigadas. Estas causas nem sempre são identificadas e estão relacionadas a um conjunto de fatores, que podem ser internos ou externos ao contexto escolar.

Frazão (2017) destaca que muitos desses fatores quase sempre são desconsiderados quando a aprendizagem não ocorre, e toda responsabilidade pela indiferença e desinteresse dos estudantes em participar das aulas de matemática recaem sobre os próprios estudantes. A análise das causas precisa ser mais profunda, avaliando também a preparação dos professores, a metodologia utilizada, o planejamento das aulas e a estrutura dos locais de ensino, não apenas os estudantes.

Pacheco e Andreis (2018) apresentam algumas possíveis causas que devem ser consideradas, como a falta de apoio da família, que cada vez mais tem se omitido da responsabilidade de educar, transferindo tal compromisso exclusivamente para a escola, gerando uma terceirização da educação, a forma como o professor conduz a aula, os primeiros contatos com o componente curricular serem desagradáveis, problemas cognitivos, negligência com relação aos estudos, falta de projetos na escola que incentivem a aprendizagem em matemática, entre outros.

Com relação aos primeiros contatos com o componente curricular, cabe destacar que nessa fase, impressões positivas e negativas ficam marcadas na mente do estudante, gerando ideias fixas que podem ser motivadoras ou desencorajadoras. Ou seja, o estudante que nos anos iniciais tem um bom desenvolvimento em matemática, ganha confiança e começa a assimilar a ideia de que se trata de um componente curricular agradável e totalmente compreensível, essa motivação sem dúvida irá contribuir para a aprendizagem de conteúdos mais complexos no futuro.

Por outro lado, o estudante que não obtém êxito sente-se incapaz, isso porque quanto mais recebe notas baixas e não consegue aprender, mais teme o componente curricular e bloqueia sua mente a todo conteúdo de matemática. Um estudante com essa dificuldade geralmente impõe limites à própria capacidade, acreditando que o conhecimento matemático é impossível para ele. Dessa forma, a tendência é que ele desista ao menor sinal de desafio, deixando de construir o conhecimento que lhe exigiria um pouco mais de esforço e confiança. 
Cardoso e Muszkat (2018) esclarecem que os estudantes se utilizam de estratégias processuais, como contar com os dedos, por exemplo, para a resolução de cálculos. Com o avanço do desenvolvimento aritmético, estas estratégias cedem espaço a outras mais eficientes, como o uso da memória para lembrar o resultado de uma multiplicação simples. O mau desenvolvimento desses processos também está relacionado com as dificuldades de aprendizagem de muitos estudantes, pois a construção de conhecimentos aritméticos serve de base para conhecimentos complexos.

Pontes (2019a) indica que um dos maiores problemas por trás do baixo rendimento em matemática, atualmente, é o fato de haver uma resistência por parte dos professores em mudar suas práticas pedagógicas visando trazer para a sala de aula metodologias que envolvam os estudantes, tal atitude tem feito com que muitos professores negligenciem os inúmeros recursos produzidos pelo avanço tecnológico. A maior parte das escolas do Brasil ainda adota uma abordagem tradicional no ensino da matemática e apresenta forte resistência à introdução de novos métodos (Pontes, 2019b).

Precisa-se que haja um processo entre o conhecimento matemático formal - conforme concebido pelos teóricos matemáticos - e o conteúdo matemático que será ensinado em sala de aula, tal processo tem como objetivo tornar a matemática formal possível de ser ensinada (Brasil, 1997). Nesse sentido, o papel do professor é imprescindível, uma vez que tem a responsabilidade de selecionar os recursos, e principalmente de organizar as mensagens e informações, de maneira que o conteúdo chegue ao estudante de forma compreensível (Diniz, Ferreira, \& da Costa, 2020).

Um dos grandes desafios a serem enfrentados pelo professor é conseguir fazer esse planejamento e comunicação de maneira a tornar o estudo da matemática algo prazeroso para o estudante. De acordo com Pontes et al. (2017) o ensinoaprendizagem de matemática precisa ser reinventado com o objetivo despertar a motivação e interesse nos estudantes, capacitando-os para enfrentar os desafios. A motivação e dedicação de professor e estudante são fatores decisivos para que a aprendizagem ocorra de forma real e concreta.

$\mathrm{Na}$ procura de novos meios de ensino da matemática, os jogos são uma alternativa para levar aos estudantes a aprender conteúdos de matemática, pois estimula a aprendizagem. O lúdico não se trata apenas de uma atividade escolar, mas de um meio para enfrentar desafios através da matemática (da Silva, de Souza, \& da Fonseca, 2021). O processo de ensino nos níveis fundamental e médio vem passando por mudanças com o objetivo de atender às necessidades educacionais atuais, e o uso de atividades lúdicas pode colaborar positivamente nesta transformação.

Faz-se necessário que o professor tenha interesse em mostrar que, ao contrário do que a maioria das pessoas pensa, a matemática está inserida na vida de todos de forma natural e compreensiva. Para que isso aconteça, é preciso romper os limites da reprodução rotineira, entendendo que muitas estratégias vêm sendo estudadas e adotadas nesse sentido, utilização do uso de jogos como alternativa. Mas qual a influência da utilização de jogos no processo de ensino-aprendizagem da matemática?

Este estudo objetiva refletir as abordagens teóricas sobre a influência das propostas pedagógicas para a aprendizagem dos estudantes e as contribuições das atividades lúdicas no desenvolvimento do processo de ensino da matemática nos níveis fundamental e médio.

Desta maneira, realizou-se uma revisão do tipo levantamento bibliográfico utilizando-se de artigos de periódicos e documentos publicados na plataforma Google Acadêmico, compreendendo o período de 2017 a 2021. Após seleção dos artigos o estudo estruturou-se de forma a possibilitar melhor compreensão das abordagens teóricas, atendendo a sequência: identificação de como as metodologias de ensino da matemática influenciam no desenvolvimento cognitivo e apresentação dos jogos como ferramentas didáticas no processo de ensino-aprendizagem da matemática.

\subsection{A matemática no ensino e aprendizagem: formas de ensino e respostas cognitivas}

É função do professor usar a criatividade para planejar e elaborar situações proveitosas, simples e práticas, capazes de motivar e despertar nos estudantes o prazer de estudar matemática ao mesmo tempo em que se sentem desafiados a utilizar o 
pensamento, buscar soluções e interagir, sendo ativos na construção do próprio conhecimento (Pacheco \& Andreis, 2018). Um dos primeiros passos para tornar o estudo da matemática interessante, é apresentá-la em um contexto próximo possível da realidade do estudante.

A matemática está inserida no contexto sociocultural, presente nas mais diversas situações do dia a dia, e precisa ser vista sob essa perspectiva, não como um conjunto de regras e fórmulas confusas e distantes. Pontes (2019b) ressalta que o desenvolvimento de vários conceitos matemáticos ocorre espontaneamente no dia a dia das crianças, mas que isso não é aproveitado na escola, fazendo com que muitas vezes exista um abismo entre a teoria vista no contexto escolar e o que se vivencia no cotidiano, abismo que precisa ser minimizado através de propostas didáticas inovadoras.

Bartho e da Mota (2020) ao escreverem sobre a Educação matemática Crítica, consideram que o ensino deve ter como base a realidade do estudante, sendo desafiado a solucionar questões e problemas matemáticos que se relacionem com o contexto social, político e econômico no qual está inserido, transformando a matemática em uma ferramenta para alcançar uma análise crítica que o permita desenvolver as próprias convicções e transformar sua realidade.

Muitos professores ainda não procuram contextualizar os conteúdos adequadamente e acabam criando cenários e contextos absolutamente irreais, distantes de qualquer concepção que o estudante consegue imaginar. Dessa forma, não se estimula o desenvolvimento do pensamento crítico, uma vez que os estudantes não entendem o que o assunto representa na realidade, e a aprendizagem acaba se tornando um processo artificial, mecânico, baseado não na compreensão, mas na memorização de conteúdos para repetir nos exercícios, característica do ensino tradicional.

De Sousa Oliveira (2019) define que o ensino tradicional da matemática corresponde à exposição pelo professor de conceitos, regras e propriedades matemáticas seguida de resolução de exercícios. Na maioria das vezes é uma educação limitada à teoria, sem demonstrar as aplicações reais que essas construções teóricas possuem. Essa abordagem não consegue suprir as necessidades de aprendizagem atuais, em que as tecnologias de informação e comunicação estão cada vez mais populares.

Destaca-se que aulas expositivas ou a utilização de métodos clássicos no ensino da matemática não implicam necessariamente em adotar o ensino tradicional, desde que o conteúdo seja apresentado de uma forma que estabeleça uma conexão com a realidade do estudante (Pontes, 2019a). Em concordância, de Sousa Oliveira (2019) acrescenta que nesse caso, primeiro deve ser explorada a aplicação do conteúdo no cotidiano ou em outras áreas do conhecimento, e só depois disso deve ocorrer a formalização do mesmo.

Diante de dificuldades envolvendo a forma de ensino predominante atualmente neste componente curricular, torna-se necessário a busca por novas propostas pedagógicas, que consigam satisfazer as necessidades cada vez mais presentes no cenário educacional e promover uma aprendizagem significativa. Várias abordagens, que buscam se afastar da tradicional, têm sido desenvolvidas e analisadas ao longo do tempo, principalmente mais recentemente, e algumas delas serão brevemente apresentadas a seguir.

Entre as tendências que vêm ganhando espaço na Educação Matemática está a Modelagem Matemática (MM), originada na Matemática Aplicada, e que vem sendo adaptada para colaborar com o ensino-aprendizagem no contexto escolar. A Modelagem Matemática dá significado aos conteúdos matemáticos utilizando suas aplicações na interpretação e compreensão de fenômenos do cotidiano para facilitar a aprendizagem, estabelecendo uma relação entre abstrato e concreto (Silva \& Almeida, 2019).

Para Souza e Barbosa (2019) a modelagem matemática no contexto escolar consiste em levar os estudantes a apresentar, investigar e compreender situações empíricas, presentes no cotidiano, utilizando a linguagem e procedimentos da matemática como ferramenta durante esse processo. Ou seja, trata-se de transformar problemas reais, não matemáticos em sua origem, em problemas - modelos - que possam ser manipulados e solucionados matematicamente. 
Veronez e Chulek (2020) consideram a MM no ensino da matemática como a tentativa de solucionar um problema que se origina fora do contexto da matemática utilizando conhecimentos e processos matemáticos, esse problema pode ser proposto por estudantes ou professor, que devem trabalhar juntos, assumindo uma postura ativa e analisando criticamente os resultados, enquanto o professor orienta e fornece o suporte necessário para que os estudantes obtenham sucesso no desenvolvimento da atividade e alcancem uma aprendizagem adequada.

Silva e Almeida (2019) ressaltam que o uso desta metodologia não se trata apenas de uma adaptação do ensino à realidade do estudante, o que poderia prejudicar a amplitude e criticidade da aprendizagem que se pretende alcançar. A modelagem matemática tem potencial para atrair os estudantes e estimular o interesse pelo conteúdo estudado, de forma que pode se tornar um caminho do conhecimento cotidiano para o formal, proporcionando uma aprendizagem ativa, crítica e reflexiva.

A aplicação da modelagem matemática como estratégia metodológica pode trazer, inicialmente, algumas dificuldades, pois professores e principalmente estudantes precisam se adaptar a uma nova postura diante da aprendizagem, porém, tais dificuldades podem ser sobrepujadas objetivando uma aprendizagem atraente e com significado. A utilização da MM no ensino da matemática pode desenvolver aspectos essenciais no contexto atual, como a motivação no estudo da matemática, mais facilidade para aprender, aplicação da matemática em outras áreas, aperfeiçoamento das habilidades exploratórias e compreensão da importância deste componente curricular no contexto sociocultural (Bastos \& Rosa, 2020).

Outra metodologia utilizada com o objetivo de adequar o ensino da matemática às demandas da sociedade atual é a Aprendizagem Baseada em Problemas (ABP), na qual os estudantes são organizados em grupos e desafiados com situaçõesproblema relacionadas ao seu contexto, área de atuação ou interesse. Em seguida, faz-se uso dos recursos disponíveis, inclusive tecnológicos, na busca por soluções, favorecendo o desenvolvimento de competências como investigação, criatividade, reflexão, trabalho em equipe e outras (Santos, Luz, \& Martins, 2020).

Pontes (2018) considera a resolução de problemas uma alternativa eficiente e vê nesse método um meio para integrar a matemática ao cotidiano e a outros componentes curriculares. Destaca-se também seu caráter investigativo, em que o estudante deve assumir uma postura participativa e traçar caminhos para encontrar soluções e construir novos conhecimentos através da investigação matemática do problema proposto, produzindo uma aprendizagem com significado.

$\mathrm{Na} \mathrm{ABP}$, após os estudantes serem divididos em pequenos grupos, são apresentados ao problema antes mesmo da exposição dos conceitos e devem trocar ideias para tentar solucioná-lo com os conhecimentos que já possuem. Nessa tentativa, perceberão a importância de aprender o conteúdo. Para de Souza e da Fonseca (2020) a ABP possui características inovadoras e pode auxiliar os estudantes a compreender melhor a aplicação prática de conteúdos teóricos, além disso, trabalhar em grupo favorece a troca de conhecimentos e o desenvolvimento cognitivo e socioemocional.

Ao escreverem sobre situações didáticas, Diniz, Ferreira e da Costa (2020) pontuam que as dificuldades geradas no processo de resolução de problemas ou desafios provocam questionamentos, reflexões e adaptações dos estudantes que têm como resultado a aprendizagem. Ao perceber dificuldades, o professor pode oferecer dicas, mas não a solução do problema, que devem ser apresentadas no intuito de fazer com que os estudantes se apropriem da situação e assumam a responsabilidade, processo chamado de devolução.

A condução do professor é essencial, pois possui a experiência e conhecimentos necessários para auxiliar seus estudantes, e pode realizar as devoluções através de perguntas, conduzindo-os ao raciocínio matemático e às soluções desejadas, não sendo necessário entregá-las sem que os estudantes tenham a oportunidade real de pensar e estabelecer conexões lógicas a respeito da situação em questão.

Blass e Irala (2020) consideram que a ABP demanda mais dedicação do professor do que o modelo tradicional, uma vez que os problemas devem ser cuidadosamente escolhidos levando em conta o interesse e a motivação dos estudantes. De 
Souza e da Fonseca (2020), destacam que o professor tem a função de incentivar o debate do problema, fornecer as informações necessárias para que todo o processo seja bem desenvolvido, inclusive indicando fontes que os estudantes podem consultar e corrigir sempre que necessário.

Souza (2019) afirma que a ABP estimula os estudantes a pesquisarem sobre os conteúdos presentes no problema que estão tentando resolver, por isso é importante que esses conteúdos sejam planejados e apresentados de maneira que os estudantes consigam identificar o que precisam estudar e aprender. O objetivo é que os estudantes construam novos conhecimentos partindo dos conhecimentos que já possuem (Blass \& Irala, 2020).

Levando-se esse objetivo em consideração, a ABP se mostra eficiente do ponto de vista cognitivo. De acordo com Molon e Franco (2019) para que haja um desenvolvimento cognitivo é necessário que estruturas novas, mais complexas que as anteriores, sejam criadas ou que as que já existam se reorganizem de maneira a possibilitar a assimilação de novos conhecimentos, nesse processo, o indivíduo primeiramente eleva um conhecimento já construído a um estágio superior de complexidade e, em seguida, a partir dessa nova construção realiza a reorganização de suas estruturas cognitivas.

Diniz, Ferreira e da Costa (2020) argumentam que para os estudantes construírem conceitos e estruturas novas capazes de dar significado ao conhecimento matemático, precisam entender os encadeamentos lógicos estabelecidos pelas definições e conceitos. Carvalho et al. (2020) discorrem sobre a Teoria da Aprendizagem Significativa, afirmando que os conhecimentos prévios servem como âncora para novos aprendizados e devem ser relacionados e conectados, estabelecendo-se organizadamente nas estruturas cognitivas. A construção de novas estruturas cognitivas concede habilidades mais complexas e expandem a capacidade de raciocinar, contribuindo significativamente para a aprendizagem.

As Tecnologias Digitais da Informação e Comunicação (TDIC), também vêm ganhando cada vez mais espaço no cenário da educação matemática, consequência atual de uma sociedade conectada. Vergara, Hinz e Lopes (2018) acreditam que essas tecnologias não podem ser desprezadas no contexto educacional e têm muito a acrescentar ao processo de ensinoaprendizagem, porém, chamam atenção ao fato de que mesmo estando presentes em diversas situações do cotidiano, a inclusão desses recursos no ambiente escolar tem ocorrido lentamente.

Neste sentido, as TDIC podem ser utilizadas como ferramentas cognitivas que possibilitem experimentar e validar conceitos. Tais ferramentas são recursos tecnológicos utilizados para auxiliar em várias etapas do processo de ensinoaprendizagem, desde a coleta e processamento de dados até sua análise e formulação de conclusões, além de serem estratégias possíveis na fase de transição do pensamento operatório concreto para o formal, promovendo aprendizagem significativa aplicada ao contexto social do estudante (Molon \& Franco, 2019).

As TDIC contribuem tanto com o ambiente escolar quanto à inclusão social, e conseguem auxiliar os estudantes a obterem melhor compreensão e visualização dos conteúdos estudados, uma vez que possibilitam ao professor fazer melhores demonstrações, que dificilmente seriam possíveis apenas com lápis e papel (Ferreira, Oliveira, \& Coelho Neto, 2019). Pode-se citar como exemplo a utilização do software Geogebra no estudo da geometria, área com grandes dificuldades de aprendizagem.

A maioria dos estudantes olha para figuras geométricas no Livro Didático, lousa, ou em quaisquer outros meios que as apresente em duas dimensões e não conseguem transferi-las e manipulá-las em pensamento. Sem essa abstração, extremamente difícil reconhecer ou elaborar sólidos geométricos, suas planificações, propriedades e conceitos, tornando boa parte do conteúdo sem sentido para o estudante. O Geogebra permite que a geometria seja desenvolvida de forma dinâmica, com a possibilidade de visualizar a construção e movimentação dos objetos, mostrando detalhes de maneira que o estudante pode obter mais informações para processar, fazer análises e chegar a conclusões.

As TDIC também possibilitam a utilização do Ensino Híbrido (EH), que é uma mescla entre momentos de ensino presencial e online. Para Souza, Torre e Peixoto (2020) o Ensino Híbrido está diretamente relacionado ao uso de metodologias 
ativas, pois gera maior participação no processo de ensino-aprendizagem com os estudantes sendo desafiados e motivados a cada atividade, tendo a responsabilidade de participarem ativamente e serem protagonistas na construção de seu conhecimento, enquanto o professor é um mediador e facilitador da aprendizagem, sempre atento ao desenvolvimento dos estudantes.

As propostas pedagógicas que fazem uso do Ensino Híbrido também podem utilizar aulas expositivas, porém esses momentos ganham sentido e atividades diferentes com a introdução de recursos tecnológicos (Vergara, Hinz, \& Lopes, 2018). Uma das metodologias derivadas do EH é a Sala de Aula Invertida, na qual os estudantes recebem e acessam os conteúdos antes das aulas, através de materiais enviados em ambientes virtuais. Com isso, o tempo de exposição em sala diminui, abrindo espaço para o esclarecimento de dúvidas, realização de projetos e experiências e resolução de problemas (Santos, Luz, \& Martins, 2020).

O processo da Sala de Aula Invertida envolve três momentos: antes, durante e depois da aula. Antes da aula o professor deve preparar o material, podendo se utilizar de textos, imagens ou vídeos, e disponibilizar no ambiente virtual, enquanto os estudantes devem acessar e estudar o conteúdo. Durante a aula há a aplicação e debate do conteúdo com atividades realizadas em grupo, ocorrendo interação e troca de conhecimentos. Após a aula acontece a avaliação do processo e, se necessário, o desenvolvimento de atividades complementares (Dziadzio \& Ferreira, 2020).

Da Silva Bizolatti e Neto (2018) destacam, que neste modelo de ensino, o momento em sala de aula não é usado pelo professor para expor todo conteúdo que já foi disponibilizado, isso se torna um incentivo para que os estudantes não deixem de estudar antecipadamente em casa e proporciona um melhor aproveitamento do tempo, que pode ser utilizado para trabalhar as dificuldades dos estudantes e desenvolver outras atividades. Outra vantagem é que como a maior parte das atividades ocorre em sala de aula, o professor pode avaliar e corrigir constantemente, ajudando o estudante a identificar mais rapidamente os pontos em que precisa melhorar.

Para Honório e Scortegagna (2017) a aplicação da Sala de Aula Invertida é benéfica para estudantes, professores e pais. Os estudantes deixam a passividade e adotam uma postura ativa diante da aprendizagem, alcançando melhores resultados e desenvolvendo competências como responsabilidade, autonomia, comunicação e trabalho em equipe, o professor pode utilizar os recursos tecnológicos para interagir melhor com os estudantes e aperfeiçoar suas práticas pedagógicas, enquanto que os pais podem participar mais da educação de seus filhos acompanhando-os durante as etapas que são realizadas em casa.

\subsection{Do ensino fundamental ao médio: utilização de jogos no ensino da matemática}

Percebe-se, em algumas pesquisas, que parte dos estudantes vem menosprezando os conteúdos matemáticos, colocando-os em lugar de pouca importância, alegando serem inúteis em seu cotidiano. Os reais motivos dessas alegações, em muitos casos, são aulas monótonas e sem a devida contextualização. De acordo com Ribeiro et al. (2018) os estudantes precisam estar preparados para as mudanças frequentes da sociedade e a escola, no seu papel de participar da formação de cidadãos críticos, precisa ter educadores e não apenas reprodutores de informação, contribuindo para a construção da cidadania do estudante e prepara-lo para lidar com as situações do cotidiano de forma ativa e pensante.

Torna-se necessário que tanto estudantes como professores façam uso do lúdico, que é uma ferramenta de importância relevante ao ensino e aprendizagem, deixando as aulas atrativas e com um bom rendimento (Moura, 2018). Com os jogos o professor traz para a sala entusiasmo e interação entre os estudantes, mostrando-os como a aprendizagem pode acontecer de forma divertida e com significado. Há inúmeras atividades lúdicas para o ensino da matemática, mas é necessário que o professor tenha interesse em aderir a essa forma de ensino e compreenda que levar novas metodologias para a sala de aula será proveitoso tanto para si como para o estudante, isso porque poderá ter contato com as dificuldades de cada um e observar onde deve melhorar (Macedo et al., 2018). 
Segundo Santana e dos Santos (2018) os indicadores educacionais revelam que grande parte dos estudantes da educação básica não tem domínio da matemática, área de conhecimento com grande relevância para a vida acadêmica, exercício da cidadania e também para o mercado de trabalho. Com base nesses indicadores se faz necessário entender que o conhecimento matemático vai além de saber resolver cálculos.

Os Parâmetros Curriculares Nacionais ( $\mathrm{PCN})$, estabelecem a necessidade do professor estimular os estudantes a procurar explicações e finalidades para as coisas, criando uma discussão em sala de aula sobre como surgiu a matemática e como ela pode ajudar nas decisões da ciência influenciando tudo ao nosso redor, assim o estudante poderá compreender o quão importante é o ensino desse componente curricular e como pode o ajudar a atuar no mundo (Brasil, 1997).

O ser humano vive em constante mudança, seus hábitos mudam, a linguagem também evolui e a forma de ensino não pode ficar para trás, no contexto contemporâneo já ficou extenuante o método de ensino com o livro impresso que surgiu após a invenção de Gutemberg até o século XIX (Valletta \& de Azevedo Basso, 2019). Se ao chegar em sala de aula o estudante se deparar com números apresentados de uma forma que não aparentem sentido, levará para a vida o conceito de uma matemática pronta e acabada, novos estilos requerem um novo olhar para o aprendizado (Alves, da Costa Quaresma \& do Nascimento, 2020).

A influência do professor e suas metodologias têm grande impacto na aprendizagem do estudante, isso porque, mesmo que este ingresse na escola já com um preconceito pelo componente curricular, o professor pode desempenhar o papel de incentivador. Percebe-se que muitos professores ainda se opõem à ideia da ludicidade, considerando que tais atividades não resolvem o problema da aprendizagem matemática, o que dificulta ainda mais a implementação de jogos em sala de aula (Silva \& D'ávila, 2020).

De acordo com Pontes et al. (2020) o uso constante da onda tecnológica para o ensino e aprendizagem da matemática vem trazendo meios que reduzem as diferenças entre o que se aprende na escola e o que se usa no cotidiano. A tecnologia está inserida em diversas áreas da humanidade, mas muitos profissionais ainda se mostram resistes quando o assunto é levar os meios tecnológicos para a sala de aula por causas que não devem lhes ser atribuídas como únicos responsáveis. Entretanto, é necessário transformar o modelo habitual das aulas em cenários motivadores e usar os recursos que já fazem parte do dia a dia de muitos estudantes no processo de ensino tende a ser muito eficiente.

Os jogos e brincadeiras na escola podem desafiar os estudantes a criarem e avaliarem métodos que levem à resolução do problema (Rostirola \& Siple, 2020). Contudo, o lúdico precisa ser aplicado com muita atenção, de modo que o estudante se divirta e aprenda, e acima de tudo, relacione os conteúdos matemáticos com seu cotidiano, é primordial que se utilizem regras, explorem as ideias e que sejam usados conhecimentos prévios da matemática. A cada dia a ludicidade vem ganhando mais espaço nas escolas com as instituições mais interessadas nas contribuições que os métodos trazem nos níveis Fundamental e Médio.

Com o ensino da matemática por meio do lúdico o professor tem um leque de possibilidades de brincadeiras, jogos, dinâmicas, entre outras atividades que facilitam a aprendizagem do componente curricular. Além de melhores resultados no currículo escolar, o professor consegue identificar as características e dificuldades de cada estudante, tendo novas possibilidades de conduzi-los até os objetivos esperados, contribuindo para a criação de valores, desenvolvimento cognitivo, trabalho em grupo, entre outras competências importantes para o desenvolvimento social, cultural e profissional.

Segundo os PCN, os jogos proporcionam verdadeiros desafios ao estudante, provocando diversão e interesse, sendo importantes no ambiente escolar, e é dever do professor analisar a viabilidade e utilidade de cada jogo baseado nos conteúdos que deseja desenvolver. O professor precisa buscar formas de apresentar a matemática de forma prazerosa e divertida ao estudante, e romper com metodologias baseadas em memorização. 
Dos Santos Silva e de Melo (2020) desenvolveram uma pesquisa com abordagem qualitativa com intuito de servir de exemplo para os professores utilizarem o lúdico em suas turmas. Os jogos realizados no ensino fundamental anos iniciais foram os Jogos das Três Cartas, Batalha de Operações e Multiplicação na Linha, e os resultados dessas atividades foram diversas resoluções dos problemas pelos estudantes com a ajuda do professor, é necessário que o professor interrogue o estudante sobre como ele conseguiu chegar nas respostas, incentivando-o a criar uma teoria e não uma resolução automática.

Pontes (2017) desenvolveu um jogo com o intuito de estimular os estudantes a desenvolverem a capacidade de somar os números naturais de forma rápida e certa. Esse jogo faz com que o aluno se anime para descobrir os resultados. O jogo tem duas figuras, a primeira com a representação de números naturais na forma de $\sum \mathrm{f}$ (i) e a segunda traz quadros com números naturais. Poderão jogar dois estudantes por vez, um perguntador e outro desafiante, o perguntador pensará em um número e o desafiante busca o acerto na relação de tentativa e erro. Os estudantes que estimularem melhor suas intuições serão os mais bem sucedidos, no decorrer do jogo o professor deverá fazer perguntas relacionadas ao assunto.

Segundo Borba, Souza, e Carvalho (2018), um dos grandes impasses da educação matemática é conseguir estimular os estudantes da Educação Básica para o raciocínio. Os raciocínios geométrico, algébrico, combinatório e aritmético, entre outros fazem parte desse desafio, de fazer com que o estudante vá além da compreensão dos problemas matemáticos, mas que crie o hábito de pensar para que isso lhes seja útil na sociedade. Um bom desenvolvimento do raciocínio faz com que o indivíduo se torne um cidadão crítico.

O estudante precisa ter contato com a Análise Combinatória desde o ensino infantil e não apenas no ensino médio. Entende-se que esse ensino não procederia com o uso de fórmulas, mas com os recursos didáticos apropriados e com um número baixo de possibilidades. Nesse sentido, pode-se usar o lúdico como ferramenta para auxiliar nessas atividades, favorecendo as crianças a desenvolverem desde cedo a ideia de Análise Combinatória.

Por serem bastante complexos, os raciocínios estatístico, combinatório e probabilístico, precisam de um tempo maior para serem desenvolvidos. Compreende-se que é primordial ao estudante ter contato desde o início da escolarização com o raciocínio, consequentemente é necessário que os professores desenvolvam atividades lúdicas que estimulem os estudantes a utilizarem métodos combinatórios, provando que é possível levar esses raciocínios à educação infantil por meio de contextos significativos, em ambientes criativos, colaborativos e estimulantes.

A sociedade muda constantemente e é preciso que o ensino das diversas áreas de conhecimento se adapte à essas mudanças, é necessário que os estudantes sejam instigados à novos desafios que se encaixem nos conhecimentos que já possuem, não apenas absorvendo o conteúdo, mas desenvolvendo habilidades (Alt et al., 2019). O lúdico não se trata apenas de uma atividade escolar, mas de um meio alternativo para enfrentar desafios através da matemática.

O jogo é um recurso pedagógico que proporciona um aprendizado diferenciado, estimulando os estudantes a buscarem soluções para os problemas, podendo despertar prazer pela matemática. Com o lúdico o estudante deixa de ser um receptor de conteúdo e passa a ser um construtor do seu próprio conhecimento (Pacífico \& Luiz, 2017). Além dos inúmeros benefícios para o estudante, o professor consegue criar diversos meios de avaliação, observando o comportamento de cada um, acompanhando suas dificuldades e domínios, entre outros benefícios.

O papel do ensino da matemática vai além de memorizar fórmulas e saber fazer cálculos, o professor deve utilizar o ensino como forma de melhorar a realidade social dos estudantes. Sabe-se, portanto, que as escolas precisam trabalhar os conceitos matemáticos de forma eficiente, aproveitando ao máximo os conhecimentos trazidos pelos estudantes para a sala de aula, para que a partir daí seja feita a introdução dos conhecimentos científicos (dos Santos, dos Santos, \& de Lima, 2020). 


\section{Metodologia}

A metodologia consistiu em um enfoque de natureza qualitativa, que demonstrasse a temática proposta assumida com caráter exploratório, descritivo e analítico (Mazo, Oliveira \& Tomazzoni, 2021). Determinou-se o delineamento constituído pela busca em fontes de produção científica publicadas em plataformas digitais, em que se constitui como pesquisa de revisão bibliográfica com análise de dados (Pereira et al., 2018).

A coleta dos dados realizou-se por meio da plataforma Google Acadêmico, empreendendo o período de publicações nacionais e internacionais em periódicos entre 2017 e 2021, com ênfase aos eixos temáticos, ensino de matemática, metodologia, educação matemática, jogos na matemática, professor de matemática e licenciatura em matemática.

Quanto a análise dos dados direcionou-se pela construção argumentativa aos aspectos comparativo e qualitativo relacionados aos conteúdos temários (Bardin, 2011). A análise subsidiou-se pela seleção de artigos que versam em seus títulos o ensino de matemática, ludicidade, jogos educativos, matemática e aprendizagem matemática, utilizando-se do recurso on line, no site WordArt.com, conhecido também como nuvem de palavras, cujas palavras de maior frequência se destacam na nuvem.

\section{Resultados e Discussão}

Os achados em publicações relacionados aos eixos temáticos, ensino de matemática, metodologia, educação matemática, jogos na matemática, professor de matemática e licenciatura em matemática, na plataforma Google Acadêmico, consistiu na primeira etapa da pesquisa, sucedendo a segunda etapa que levou em consideração o aspecto longitudinal para o período dos últimos cinco anos.

Por fim, a última etapa consistiu em selecionar por relevância as publicações cujos conteúdos temáticos e, sobretudo, sua relação métrica quanto a importância e influência dos periódicos em meio científico, auferidos pela Coordenação de Aperfeiçoamento de Pessoal de Nível Superior (CAPES), conferidos pelo indicador Qualis. Desta forma, as três etapas formaram o crivo para coleta de dados desta pesquisa, resultando na seleção de 45 artigos científicos e na Tabela 1 destacam-se os principais artigos referentes aos eixos ensino de matemática e jogos na matemática no período de 2019 a 2021.

Tabela 1. Artigos em destaque recuperados da plataforma Google Acadêmico, referentes aos eixos ensino de matemática e jogos na matemática, no período de 2019-2021.

\begin{tabular}{c|c|c|cc}
\hline Eixo Temático & Periódico & ISSN & QUALIS/CAPES & QUANT. \\
\hline Ensino de Matemática & Revista De Educação Matemática & $2526-9062$ & A3 & 1 \\
\hline Ensino de Matemática & Research, Society and Development) & $2525-3409$ & A3 & 2 \\
\hline Ensino de Matemática & $\begin{array}{c}\text { Revista Paranaense de Educação } \\
\text { Matemática }\end{array}$ & $2238-5800$ & A3 & 1 \\
\hline Jogos na matemática & Revista De Educação Matemática & $2526-9062$ & A3 & 1 \\
\hline Jogos na matemática & Research, Society and Development & $2525-3409$ & A3 & 2 \\
\hline
\end{tabular}

Fonte: Autores (2021).

Observa-se na Tabela 1 uma tendência em publicações que propõem refletir sobre a temática ensino de matemática, seguida de abordagens didático pedagógicas que demonstram a ludicidade como prática pedagógica no ensino de matemática.

As proposições escritas elencam uma série de mecanismos e métodos teoricamente relevantes ao papel do professor na condução do ensino de matemática, além da demonstração de evidências que auferem fragilidades no modelo tradicional de ensino desde a fase inicial da vida de um estudante.

São fundamentos que buscam o desenvolvimento de linhas argumentativas com enfoque na necessidade de mudanças e perspectivas de adaptações no cenário educacional. Contudo, proposições de novos métodos e modelos de ensino como a 
ABP, a MM e a Modalidade de Ensino Híbrido por meio do uso das TDIC, características do ensino conhecido como Sala de Aula Invertida.

Na Figura 1 constam as palavras-chave que se destacam, relacionadas devido sua importância e recorrência nos artigos selecionados no período de 2017-2021.

Figura 1. Nuvem de palavras originadas a partir dos títulos dos artigos pesquisados, depositados na plataforma Google Acadêmico.

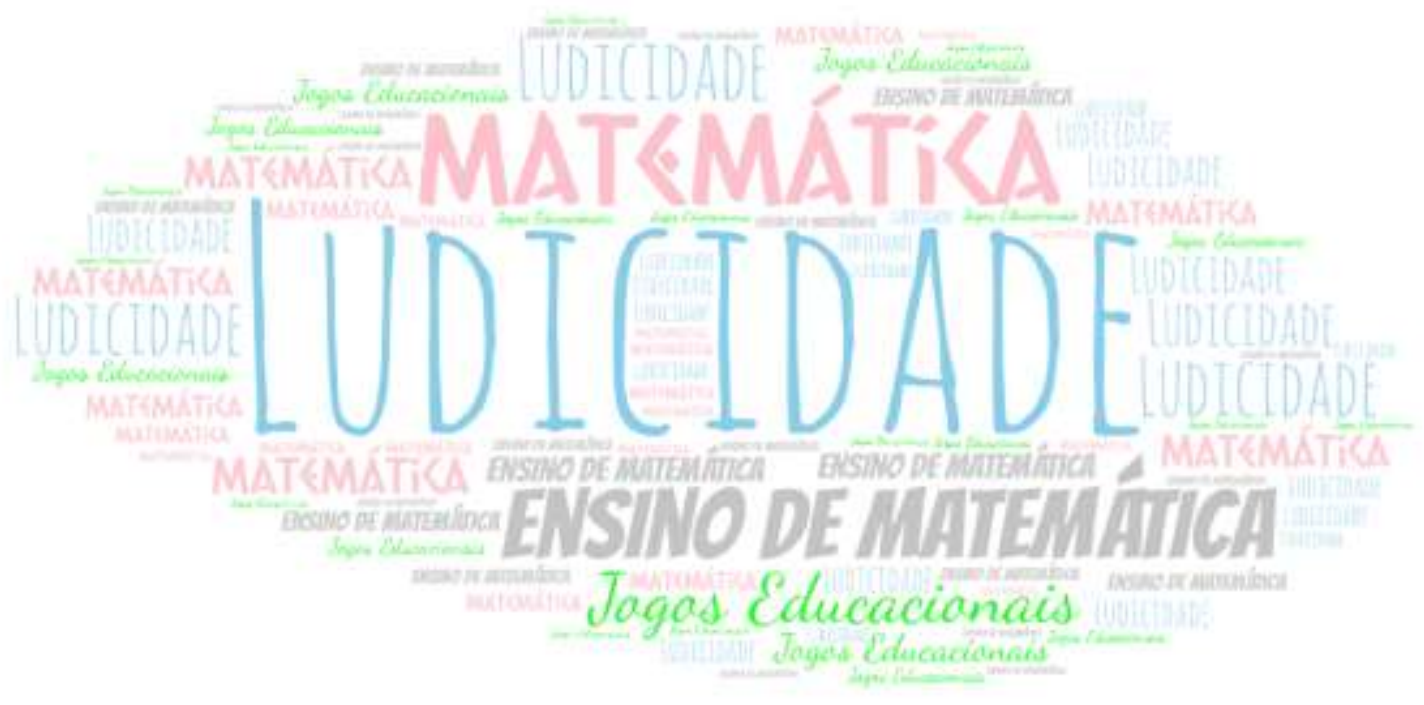

Fonte: Autores (2021)

Na Figura 1 observa-se a recorrência dos termos ludicidade, matemática e ensino de matemática nos títulos dos artigos selecionados. O termo jogos educacionais não se faz expressivo, apesar da correlação direta com o método lúdico, percebeu-se que as abordagens teóricas demonstram incentivo para sua realização em sala de aula.

Desta forma o ensino de matemática com novas abordagens didáticas traz uma discussão em meio científico como emergente e necessárias, a criatividade e o repensar o ensino desde a formação acadêmica do professor ao exercício da licenciatura, requer mudança de comportamentos e apoio de todos os atores envolvidos no processo de ensino brasileiro.

A ludicidade não pode ser entendida como didática unicamente aos cursos de pedagogia, mesmo que em algumas instituições o método sequer consta no plano pedagógico do curso (da Silva \& Passos, 2019). Desta maneira, o enfrentamento das dificuldades enfrentadas pelos estudantes nos anos iniciais do ensino fundamental pode ser minimizado com o exercício da licenciatura em matemática balizada em uma formação profissional inovadora e liberta dos mecanismos tradicionais que massificam o ensino ordeiro, com apelo a memorização de fórmulas e busca por resultados pré-definidos, que a propósito não deve recair o sentimento de culpabilidade ao professor.

A criação de cenários redirecionado aos estudantes como protagonistas da própria construção do conhecimento não isenta a responsabilidade do professor em prover condições e situações para que isso ocorra (Santos \& Alves, 2017). Entretanto, a utilização de novos modelos de ensino como MM, ABP e EH, não caracteriza abandono do modelo tradicional de ensino, motivo pelo qual a prática didática pelo método da ludicidade surge como instrumento de ensino e apoio a mudanças no ensino da matemática no ensino fundamental e médio. 


\section{Conclusão}

O sucesso do ensino de matemática depende de diversos fatores, a importância de explorar os recursos e metodologias disponíveis estão em constante processo de avaliação e aperfeiçoamento da prática pedagógica. Além de estimular atividades que anulem a passividade intelectual, para que os estudantes tornem-se ativos diante da aprendizagem e que colaborem com seu desenvolvimento cognitivo, de modo que se inicie um processo onde o estudo da matemática torne-se cada vez mais interessante. A compreensão dos símbolos e conteúdos matemáticos, assim como a maneira com que eles se relacionam ao cotidiano são relevantes ao desenvolvimento da educação de maneira geral.

Portanto, com as reflexões realizadas por meio da análise do referencial teórico selecionado, pode-se concluir que o ensino da matemática nos níveis Fundamental e Médio, são praticados no alicerce da pedagogia tradicional em sua maioria, evidenciado que mudanças nas estratégias de ensino se fazem necessárias, por meio de uma transformação no pensar a licenciatura em matemática, que abranja fatores dentro e fora da escola. Objetivando quebrar a referência em torno do componente curricular como complexo de se aprender, tornando os estudantes mais receptivos ao estudo.

Por fim, acredita-se que a temática contribui para promover discussões em meio científico, alimentando o incentivo a pesquisa e desenvolvimento de novas práticas pedagógicas. E nesta perspectiva sugere-se novos estudos sobre o tema para visibilização e caracterização de mudanças no cenário educacional, sobretudo, no ensino de matemática e na formação do professor.

\section{Agradecimentos}

Ao Instituto Federal de Educação, Ciência e Tecnologia de Pernambuco - IFPE; ao Programa Universidade Aberta do Brasil - UAB; à Coordenação de Aperfeiçoamento de Pessoal de Nível Superior - CAPES

\section{Referências}

Alt, A. L. S., Monteiro, E. S., Nascimento, F. F. M., \& Castro, F. M. B. (2019). Sala de apoio e ludicidade: adaptação de jogos como auxilio da aprendizagem. Research, Society and Development, 8(6). https://doi.org/10.33448/rsd-v8i6.1051

Alves, L. C., da Costa Quaresma, P., \& do Nascimento, D. L. (2020). Estilos de aprendizagem de alunos do $3^{\circ}$ ano do ensino médio a partir do Novo ILS (New Index of Learning Styles). Research, Society and Development, 9(11). https://doi.org/10.33448/rsd-v9i11.9598

Bardin, L. (2011). Análise de conteúdo. São Paulo: Edições 70.

Bartho, V. D. D. O. R., \& da Mota, N. A. (2020). Aspectos da Concepção de Educação Matemática Crítica em Material Didático de Matemática Financeira. Perspectivas da Educação Matemática, 13(31), 1-18. 10.46312/pem.v13i31.7830

Bastos, T. A., \& Rosa, M. (2020). Modelagem na Educação Matemática para o desenvolvimento de conceitos de Análise Combinatória. Educação Matemática Debate, (4), 16. 10.24116/emd.e202012

Blass, L., \& Irala, V. B. (2020). O uso da Aprendizagem Baseada em Problemas (PBL) como metodologia de ensino em aulas de Cálculo Numérico. Revista De Educação Matemática, 17. doi.org/10.25090/remat25269062v17id360

Borba, R. E. S. R., SOUZA, L., \& CARVALHO, J. (2018). Desafios do ensino na Educação Básica de Combinatória, Estatística e Probabilidade. Revista de Educação Matemática e Tecnológica Iberoamericana-Em Teia, 9(1), 1-24. https://doi.org/10.36397/emteia.v9i1.231908

Brasil. Secretaria de Educação Fundamental. Parâmetros curriculares nacionais: matemática. Brasília: MEC/SEF, 1997, 156p.

Cardoso, T. D. S. G., \& Muszkat, M. (2018). Aspectos neurocientíficos da aprendizagem matemática: explorando as estruturas cognitivas inatas do cérebro. Revista Psicopedagogia, 35(106), 73-81. https://cdn.publisher.gn1.link/revistapsicopedagogia.com.br/pdf/v35n106a09.pdf

Carvalho, R. da S., Zanatta, S. C., Carvalho, H. A. P. de, \& Royer, M. R. (2020). Uma proposta de Ciências, Tecnologia, Engenharia, Artes e Matemática (STEAM) - o 'carrinho de luz'. Research, Society and Development, 9(7). https://doi.org/10.33448/rsd-v9i7.4673

Diniz, I. G. A., Ferreira, J. L., \& da Costa, A. P. (2020). O ensino de função polinomial do primeiro grau: um estudo sob a ótica da Teoria das Situações Didáticas numa turma do Ensino Médio. Revista De Educação Matemática, 17. doi.org/10.37001/remat25269062v17id363

Dziadzio, S. J., \& Ferreira, C. R. (2020). Sala de aula invertida: caracterização e reflexões das três etapas do método no ensino de matemática. Revista Paranaense de Educação Matemática, 9(20), 411-425. https://doi.org/10.33871/22385800.2020.9.20.411-425 
Ferreira, M. E. D., Oliveira, S. B., \& Coelho Neto, J. (2019). Objetos de Aprendizagem e o Ensino da Matemática: um mapeamento dos recursos utilizados em sala de aula. Research, Society and Development, 8(1). https://doi.org/10.33448/rsd-v8i1.629

Frazão, F. U. S. (2017). A importância da construção de algumas figuras geométricas utilizando o jogo xadrez para o desenvolvimento cognitivo do aluno e para sua mudança de comportamento. Repositório Institucional UEA, 1-15. http://repositorioinstitucional.uea.edu.br//handle/riuea/419

Honório, H. L. G., \& Scortegagna, L. (2017). Invertendo a sala de aula: processo para a implementação da metodologia sala de aula invertida com elementos de colaboração no ensino de matemática. Revista de Educação, Ciências e Matemática, 7(2), 206-219. http://publicacoes.unigranrio.edu.br/index.php/recm/article/view/4414

Macedo, S. D. S., Correa, S. F., Rocha, M. M. O., Miranda, R. S., \& Pires, V. B. (2018). Uso de material reciclado para a construção de material didático no ensino da matemática. Research, Society and Development, 8(3). http://dx.doi.org/10.33448/rsd-v8i3.756

Mazo, A., Oliveira, R. K. D., \& Tomazzoni, E. L. (2021). Análisis bibliográfica y sistemática de la literatura académica de los términos "ciudades inteligentes", "turismo" y “competitividad". Turismo: Visão e Ação, 23(1), 148-168. https://doi.org/10.14210/rtva.v23n1.p148-168

Molon, J., \& Franco, S. R. K. (2019). GeoGebra: ferramenta cognitiva para o desenvolvimento do pensamento operatório formal. In Anais dos Workshops do Congresso Brasileiro de Informática na Educação 8(1), 650-656. 10.5753/cbie.wcbie.2019.650

Moura, E. S. (2018). Importância do lúdico para o ensino da matemática no primeiro ano do ensino fundamental. Revista ISESPI, 1(1), 8-8. https://www.faculdadeisespi.com.br/revista/index.php/isespi/article/view/2

Pacheco, M. B., \& Andreis, G. D. S. L. (2018). Causas das dificuldades de aprendizagem em Matemática: percepção de professores e estudantes do $3^{\circ}$ ano do Ensino Médio. Revista Principia, João Pessoa, 38, 105-119. DOI: http://dx.doi.org/10.18265/1517-03062015v1n38p105-119

Pacífico, M., \& Luiz, R. S. (2017). A importância dos jogos no ensino da matemática. Revista Tecer, 10(19), 127-136. https://www.metodista.br/revistasizabela/index.php/tec/article/view/1450/897

Pereira, A. S. et al. (2018). Metodologia da pesquisa científica. [e-book]. Santa Maria. Ed. UAB/NTE/UFSM. Disponível em: https://repositorio. ufsm. br/bitstream/handle/1/15824/Lic_Computacao_Metodologia-Pesquisa-Cientifica. pdf.

Pontes, E. A. S. (2017). Os números naturais no processo de ensino e aprendizagem da matemática através do lúdico. Diversitas Journal, 2(1), 160-170. 10.17648/diversitas-journal-v2i4.453

Pontes, E. A. S. (2018). Modelo de ensino e aprendizagem de matemática baseado em resolução de problemas através de uma situação-problema. Revista Sítio Novo, 2(2), 44-56. http://dx.doi.org/10.47236/2594-7036.2018.v2.i2.44-56p

Pontes, E. A. S. (2019a). Os Quatro Pilares Educacionais no Processo de Ensino e Aprendizagem de Matemática. Revista Iberoamericana de Tecnología en Educación y Educación en Tecnología, (24), 15-22. 10.24215/18509959.24.e02

Pontes, E. A. S. (2019b). Questões conceituais de um professor sobre o processo de ensino e aprendizagem de matemática na educação básica. Research, Society and Development, 8(4). https://doi.org/10.33448/rsd-v8i4.932

Pontes, E. A. S., da Silva, A. J. C., de Cerqueira Neto, A. A., de Almeida, E. C., dos Santos, M. A. B., \& de Carvalho Araújo, N. (2020). Verificação Experimental de um Produto Educacional: um jogo matemático desenvolvido a partir da ideia intuitiva de uma progressão aritmética. Revista Psicologia \& Saberes, 9(18), 114-122. https://doi.org/10.3333/rps.v9i18

Pontes, E. A. S., de Miranda, J. R., dos Santos, J. F., de Amorim, I. A., \& da Silva, M. F. (2017). Matemática para todos: uma ação extensionista visando o desenvolvimento cognitivo e intelectual de estudantes da educação básica. Revista Psicologia \& Saberes, 6(7), 20-28. https://doi.org/10.3333/ps.v6i7.742

Ribeiro, N. A., Luccas, S., Damin, W., \& dos Santos, H. D. A. (2018). Ensino de Probabilidade: contribuições de um jogo didático. Unión: Revista iberoamericana de educación matemática, (52), 201-217. https://dialnet.unirioja.es/servlet/articulo?codigo=6393000

Rostirola, S. C. M., \& Siple, I. Z. (2020). Materiais lúdicos como instrumentos de ensino-aprendizagem-avaliação de análise combinatória no Ciclo de Alfabetização. Revista De Educação Matemática, (17), 18. doi.org/ 10. 37001 /remat25269062v17 id258

Santana, S., \& dos Santos, W. O. (2018). Jogos Educativos no Ensino de Matemática: Qual a Melhor Abordagem?. In Anais do Workshop de Informática na Escola 24(1). http://dx.doi.org/10.5753/cbie.wie.2018.80

Santos, A. P. R. A., \& Alves, F. R. V. (2017). A teoria das situações didáticas no ensino das Olimpíadas de Matemática: Uma aplicação do Teorema de Pitot. Indagatio Didactica, 9(4), 279-296. https://doi.org/10.34624/id.v9i4.976

Santos, M. E. K. L. dos, Luz, J. O. C. da, \& Martins, P. B. (2020). A utilização de metodologias ativas no processo de ensino/aprendizagem de matemática alinhadas a Base Nacional Comum Curricular. Research, Society and Development, 9(5). https://doi.org/10.33448/rsd-v9i5.2989

Silva, A. J. N., de Souza, I. dos S., \& da Fonseca, S. S. (2021). The Mathematical Education Laboratory and its ludic-pedagogical potentialities: some itinerant experiences. Research, Society and Development, 10(2). https://doi.org/10.33448/rsd-v10i2.12697

Silva Bizolatti, A., \& Neto, J. C. (2018). Sala de Aula Invertida: possíveis aproximações para o ensino da Matemática. Revista Thema, 15(3), 848-859. http://dx.doi.org/10.15536/thema.15.2018.848-859.929

Silva, A. J. N., \& Passos, C. B. (2019). Conhecendo mais sobre a ludicidade, formação de professores e ensino de matemática no curso de pedagogia da UFSCAR. Revista Brasileira de Pesquisa (Auto) biográfica, 4(10), 264-282. 10.31892/rbpab2525-426X.2019.v4.n10.p264-282

Santos Silva, D., \& De Melo, J. B. (2020). O lúdico no ensino da matemática: análise de jogos didáticos para o ensino fundamental. Multidebates, 4(4), 73-87. http://revista.faculdadeitop.edu.br/index.php/revista/article/view/261 
Research, Society and Development, v. 10, n. 6, e26010615756, 2021

(CC BY 4.0) | ISSN 2525-3409 | DOI: http://dx.doi.org/10.33448/rsd-v10i6.15756

Santos, C., dos Santos, D. P., \& de Lima, M. A. (2020). A Importância da Atividade Lúdica na Educação Matemática. Revista Psicologia \& Saberes, 9(14), 79-87. https://doi.org/10.3333/rps.v9i14

Sousa Oliveira, M. (2019). Uma reflexão sobre a ideia de superação do ensino tradicional na educação matemática: a dicotomia entre a abordagem clássica e abordagens inovadoras em foco. Revista BOEM, 7(14), 79-93. http://dx.doi.org/10.5965/2357724X07142019079

Souza, C. A., \& da Fonseca, R. F. (2020). Considerações acerca do uso da Aprendizagem Baseada em Problemas (PBL) em um Curso Técnico Integrado ao Ensino Médio. Revista De Educação Matemática, 17. DOI: doi.org/10.37001/remat25269062v17id443

Silva, A. C., \& D'Ávila, C. M. (2020). Prática pedagógica lúdica de professores que ensinam matemática nos anos iniciais do ensino fundamental. REAMECRede Amazônica de Educação em Ciências e Matemática, 8(2), 232-252. 10.26571/reamec.v8i2.10009

Silva, N. R. da, \& Almeida, J. J. P. de. (2019). Modelagem matemática: uma alternativa metodológica para o ensino básico. Research, Society and Development, 8(3). https://doi.org/10.33448/rsd-v8i3.805

Souza, D. D. (2019). O uso de problemas matemáticos no Ensino Superior sob o viés da Aprendizagem Baseada em Problemas. Revista de Educação Matemática, 16(22), 270-283. doi.org/10.25090/remat25269062v16n222019p270a283

Souza, E. G., \& Barbosa, J. C. (2019). A aprendizagem de regras do sistema matemático escolar na modelagem matemática. Revista latinoamericana de investigación en matemática educativa, 22(1), 39-66. 10.12802/relime.19.2212

Souza, P. de A., Torre, O. A. P. L., \& Peixoto, G. T. B. (2020). Rotação por estações: experimentação de uma proposta didática a alunos do ensino médio, no estudo de progressões por meio dos fractais. Research, Society and Development, 9(10). https://doi.org/10.33448/rsd-v9i10.8804

Valletta, D., \& de Azevedo Basso, M. V. (2019). A ubiquidade dos games no ensino da matemática. ETD: Educaçao Temática Digital, 21(3), 782-796. 10.20396/etd.v21i3.8652109

Vergara, A. C. E., Hinz, V. T., \& Lopes, J. L. B. (2018). Como Significar a Aprendizagem de Matemática Utilizando os Modelos de Ensino Híbrido. Revista Thema, 15(3), 885-904. http://dx.doi.org/10.15536/thema.15.2018.885-904.962

Veronez, M. R. D., \& Chulek, C. (2020). Modelagem Matemática: um olhar semiótico. Educação Matemática Debate, 4(10). 10.24116/emd.e202014 